\title{
Genetic Diversity Among Varieties and Hybrid Lines of Pea (pisum sativum 1.) as Revealed by Morphological Traits and SSR Markers
}

\author{
A. Badr ${ }^{1^{*}}$, H. S. Ahmed ${ }^{2}$, M. Hamouda ${ }^{2}$ and Salwa F. Badr ${ }^{2}$ \\ ${ }^{I}$ Botany and Microbiology Department, Faculty of Science, \\ Helwan University, 11790 Cairo and ${ }^{2}$ Botany Department, \\ Faculty of Science, Tanta University, 31527 Tanta, Egypt.
}

\begin{abstract}
ENETIC diversity among five pea varieties and 20 hybrid lines was investigated based on variation in 33 morphological traits and polymorphism created by 19 SSR primers. Measurements of morphological traits clearly indicated that hybrids generally have more vigor compared to their parents. The analysis of genetic diversity using the NTSYS-pc and the CAP software produced UPGMA, NJ and CAP trees of similar topologies. In all trees, Var. Sugarless and its hybrids were separated as one group, Var. Master B and most of its hybrids as another group and Var. Lincoln, Var. Little Marvel and Var. Luxer and some of their hybrids were distinguished as different groups. Close distance was particularly found between Var. Sugarless and the hybrids Sugarless x Master B, Sugarless x Lincoln, Sugarless x Little Marvel, Sugarless x Luxer, and Luxer x Sugarless and Lincoln $x$ Sugarless. On the other hand, low distance was observed between Var. Master B and the hybrids Master B x Lincoln, Master B x Little Marvel, Master B x Luxer, Little Marvel x Master B and Luxer x Master B. These findings may be used to guide future breeding of pea genotypes into commercial lines.
\end{abstract}

Keyword: Pea, Pisum sativum, Genetic variation, Molecular markers, ISSR, Plant breeding.

In recent years, the increasing demand for protein rich food for human nutrition and for animal feed have led to greater interest in pea (Pisum sativum L.) as a protein source (Santalla et al., 2001 and, et al., 2010). To meet the increasing demand of pea there is great need to breed new cultivars through crossing existing cultivars with desired traits and selecting progeny with improved performance and improved combination of traits (Knight, 2003 and Gatti et al., 2011). Ana Paula et al. (2008) reported significant differences in all the quantitative traits in field pea breeding lines. In pea, breeding programs aim for high yield with homogeneous maturity and resistance to abiotic and biotic stresses (Baranger et al., 2004; Bliss, 2007 and Ellis, 2011). In pea, high variance for grain yield, biomass and pods per plant indicate the scope of improvement through simple selection for high mean values for these traits (Saeed et al. (2009). This approach was applied to characterize the pea germplasm conserved in Turkey Sarıamış et al. (2010) and to study the diversity of pea accessions of different origins in Argentina, based on morphological data (Gatti et al., 2011) and from different parts of the world (Nisar et al. (2011).

"Author for correspondence: abdelfattahbadr@yahoo.com 
Molecular markers have been applied to address genetic diversity and breeding of peas (Samec et al., 1998; Simioniuc et al., 2002; Baranger et al., 2004 and Cieslarová et al., 2012) and have great potential to speed up the process of developing improved cultivars. The simple sequence repeats (SSR), also known as microsatellites, have been used on various collections of peas as a sole source of variation (Burstin et al., 2001; Choudhury et al., 2006; Nasiri et al., 2009 and Sarkamı et al., 2010) and in combination with morphological variation (Tar'an et al., 2005; Smykal et al., 2008; Tihomir et al., 2009; Sarikamis et al., 2010 and Smýkal et al., 2012). Although several hundreds of simple sequence repeats (SSR) markers have been identified (Burstin et al., 2001; Loridon et al., 2005; Zong et al., 2008 and Gong et al., 2010). Additional SSR markers with polymorphism are needed, for the development of linkage maps for use in breeding new varieties with resistant to white mold disease and for mapping studies (Zhuang et al., 2013).

The relatively narrow gene pool of peas (Heath and Hebblethwaite, 1985) and the heavy use of a small number of parents by competing breeding programs have led to a low genetic diversity among pea cultivars (Baranger et al., 2004). Genetic diversity of this crop may be increased by incorporating genes from different varieties in new genotypes (Simioniuc et al., 2002). In the current study we investigate the genetic diversity in five pea varieties and 20 hybrid lines based on variation in morphological traits with emphases on agronomic traits. In addition SSR fingerprinting has been carried out for all 25 genotypes.

\section{Material and Methods}

Five pea varieties (Master B, Little Marvel, Lincoln, Luxer, and Sugarless) were selected for the present study. Seeds of these varieties were kindly provided by the Agriculture Research Centre (ARC) in Giza, Egypt. The five pea varieties were grown for one season (October 2010 to April 2011) and hybridized together to produce 20 hybrid lines. The parent varieties and their 20 hybrids were grown for one season (October 2011 to April 2012). Morphological description of the parent plants and their hybrids was carried out on 33 morphological traits based on the guidelines of the International Union for the Protection of New Varieties of Plants (UPOV) and the USDA protocol for objective description of pea (May 2010). At least five plants from each variety were described and a total of 33 quantitative and qualitative traits were recorded.

Nineteen SSR primer pairs were selected to reveal SSR polymorphism among the five varieties of pea and their hybrids, based on the level of polymorphism in pea germplasm as reported in previous studies particularly those by Burstin et al. (2001) and Tar'an et al. (2005). The used primer pairs (Fermentas, EU) and the expected fragment size are listed in Table 1. The protocol used for SSR fingerprinting did not involve DNA extraction and is a new protocol for SSR analysis developed by Sigma, Germany. For SSR fingerprinting seeds of parents and their hybrids were grown in pots in the laboratory at $20^{\circ} \mathrm{C}$. A small disc of fresh leaves taken from actively growing

Egypt. J. Bot., Vol. 55, No. 1 (2015) 
seedlings was taken using the $50 \mathrm{~mm}$ Harris Uni-core puncher supported by the cutting mat. The disc was added directly into $25 \mu$ l PCR reaction mix containing $25 \mathrm{mM} \mathrm{MgCl2}$, 1X PCR buffer, $200 \mu \mathrm{M}$ dNTPs (Applied Biosystems), $1 \mathrm{U}$ of Taq DNA polymerase (Applied Biosystems, Ampli-Taq Gold), 2 pmole of each primer. Polymerase chain reaction was made for amplification of SSR loci according to the procedure described by Burstin et al. (2001) with modifications in the quantity of genomic DNA and annealing temperature.

TABLE 1. List of the 19 SSR primers used in this study showing primer sequences and expected fragments size range for each primer.

\begin{tabular}{|c|l|l|l|c|}
\hline Serial & \multicolumn{1}{|c|}{$\begin{array}{c}\text { Primer } \\
\text { name }\end{array}$} & \multicolumn{1}{|c|}{ Forward sequence } & \multicolumn{1}{|c|}{ Reverse sequence } & $\begin{array}{c}\text { Fragment } \\
\text { size (bp) }\end{array}$ \\
\hline 1 & A-5 & gta aag cat aag ggg att ctc at & cag ctt tta act cat ctg aca ca & $323-430$ \\
\hline 2 & A-6 & ctt aag aga gat taa atg gac aa & cca act cat aat aaa gat tca aa & $156-167$ \\
\hline 3 & A-9 & gtg cag aag cat ttg ttc aga t & ccc aca tat att tgg ttg gtc a & $364-385$ \\
\hline 4 & AA-205 & tac gca atc ata gag ttt gga a & aat caa gtc aat gaa aca agc a & $216-246$ \\
\hline 5 & AA-473 & caa tcg atc aga cag tcc cct a & aag ctc acc tgg tta tgt ccc t & $327-406$ \\
\hline 6 & AA-476 & tag ttt tga act ttg gcc gta t & cac acc cta atc tag gct atc c & $186-348$ \\
\hline 7 & AA-430942 & 'ctg gaa ttc ttg cgg ttt aac & cgt ttt ggt acg atc gag cat & $178-185$ \\
\hline 8 & AD-21 & tat tct cct cca aaa ttt cct t & gtc aaa att agc caa att cct c & $200-275$ \\
\hline 9 & AD-141 & aat ttg aaa gag gcg gat gtg & act tcc tcc aac atc caa cg a & $248-350$ \\
\hline 10 & AD-186 & tca atg cgt gtt gat cga gga & cca tgc ttt gca ccg aaa gta a & $270-332$ \\
\hline 11 & AD-237 & aga cat ttg gtg tca tca gtg & tgt tta ata caa cgt gct cct c & $234-374$ \\
\hline 12 & AD-270 & ctc atc tga tgc gtt gga tta $g$ & agg ttg gat ttg ttg ttt gtg & $189-255$ \\
\hline 13 & AF-016458 & cac tca taa cat caa cta tct ttc & cga atc ttg gcc atg aga gtt gc & $162-177$ \\
\hline 14 & B14 & gag tga gct ttt tag ctt gca gcc t & tgc ttg ag aac agt gac tcg ca & $367-415$ \\
\hline 15 & B-16 & gca ttt gtg cag ttt caa ttt cg & cca att acg gac aat gtt tga tca & $387-435$ \\
\hline 16 & PSAS & ggt gat aac tat ttg gct cat c & gta gat ttc tcc att cac ctg & $223-229$ \\
\hline 17 & PSBOX-13.1 & gaa cta gag ctg ata gca tgt & gca tgc aaa aga acg aaa cag g & $244-566$ \\
\hline 18 & X51594 & caa cca gcc att ata cac aaa ca & ggc aat aaa gca aaa gca ga & $221-367$ \\
\hline 19 & X-78581 & ctg cta tgc tat gtt tca cat c & ctt tgc ttg caa ctt agt aac ag & $90-105$ \\
\hline
\end{tabular}

The PCR amplification was performed using Bio-Rad thermo-cycler according to the following cycle profile: initial denaturation at $95^{\circ} \mathrm{C}$ for $10 \mathrm{~min}$, followed by 35 cycles of $30 \mathrm{sec}$ at $94^{\circ} \mathrm{C}, 30 \mathrm{sec}$ at $60^{\circ} \mathrm{C}$ and $30 \mathrm{sec}$ at $72^{\circ} \mathrm{C}$, and $5 \mathrm{~min}$ at $72^{\circ} \mathrm{C}$ for final product extension. Equal amounts $(10 \mu \mathrm{l})$ of PCR SSR products were electrophoresed on $1.8 \%$ agarose gels. DNA ladder (100 bp) was used as a molecular size marker. Electrophoresis was carried out for 1 hour at 120 volt and $100 \mathrm{~mA}$. The gel was then removed and viewed under UV light using illumination box and photographed by using digital camera (Kodak AF 3X). The names of pea varieties examined in this study and their hybrids have been given symbols from V01 to V25 as given in Table 2 and in the Fig.1-3.

\section{Data analysis}

The morphological traits have been regarded as three types:- (1) quantitative characters that were given codes ranging between 0 and 3 depending on the variation 
in the average value for the measured traits. (2) presence/absence traits that were given codes as 1 for presence and 0 for absence and, (3) qualitative traits were given codes from 0 to 4 depending on the state of these traits. For SSR fingerprinting, unambiguous products were scored for analysis and were coded 0 or 1 depending on their absence or presence in the fingerprinting profiles of pea varieties and their hybrids. Molecular size for SSR bands were calculated using the Lab Image software program produced by (Kapelan $\mathrm{GmbH}$ Co, Germany). The number and type of bands, as polymorphic, monomorphic and unique, in the SSR fingerprinting of the examined genotypes are given in Table 2.

TABLE 2. Total number of SSR bands for each variety or hybrid, number of polymorphic, and unique bands) and percentage of polymorphism for the five varieties of pea and their hybrids as revealed by SSR fingerprinting.

\begin{tabular}{|c|c|c|c|c|c|}
\hline Code & Variety or hybrid & $\begin{array}{l}\text { No. of } \\
\text { bands }\end{array}$ & \begin{tabular}{|c|}
$\begin{array}{c}\text { No. of } \\
\text { monomorphic } \\
\text { bands }\end{array}$ \\
\end{tabular} & $\begin{array}{c}\text { No. of } \\
\text { polymorphic } \\
\text { bands }\end{array}$ & $\begin{array}{c}\% \\
\text { Polymorphism }\end{array}$ \\
\hline V01 & Master B & 72 & 29 & $41+2$ unique & 59.7 \\
\hline V02 & Master B $\hat{\sigma} \times$ Lincoln $q$ & 53 & 29 & 24 & 45.3 \\
\hline V03 & Master B $\delta \times$ Little Marvel $q$ & 57 & 29 & 28 & 49.1 \\
\hline V04 & Master B $\hat{o} \times$ Sugarless $q$ & 48 & 29 & 19 & 40.4 \\
\hline V05 & Master B $\hat{\sigma} \times$ Luxer $q$ & 52 & 29 & 23 & 44.2 \\
\hline V06 & Lincoln & 61 & 29 & 32 & 51.6 \\
\hline V07 & Lincoln $\hat{\delta} \times$ Master B $q$ & 50 & 29 & 21 & 42.0 \\
\hline V08 & Lincoln $\delta \times$ Little Marvel $q$ & 44 & 29 & 15 & 34.1 \\
\hline V09 & Lincoln $\hat{\delta} \times$ Sugarless $q$ & 45 & 29 & 16 & 35.6 \\
\hline V10 & Lincoln $\hat{\delta} \times$ Luxer $q$ & 51 & 29 & 22 & 43.1 \\
\hline V11 & Little Marvel & 61 & 29 & 32 & 51.6 \\
\hline V12 & Little Marvel $\hat{\delta} \times$ Master B $q$ & 50 & 29 & 21 & 42.0 \\
\hline V13 & Little Marvel $\hat{\delta} \times$ Lincoln $\not$ & 48 & 29 & 19 & 39.6 \\
\hline V14 & 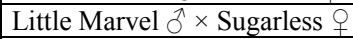 & 46 & 29 & 17 & 36.9 \\
\hline V15 & Little Marvel $\hat{\delta} \times$ Luxer $q$ & 47 & 29 & 18 & 38.3 \\
\hline V16 & Sugarless & 58 & 29 & 29 & 50.0 \\
\hline V17 & Sugarless $\hat{\sigma} \times$ Master B 오 & 47 & 29 & 18 & 38.3 \\
\hline V18 & Sugarless $\hat{\delta} \times$ Lincoln $\phi$ & 49 & 29 & 20 & 40.8 \\
\hline V19 & Sugarless $\hat{\partial} \times$ Little Marvel + & 53 & 29 & 23 & 43.4 \\
\hline V20 & Sugarless $\hat{0} \times$ Luxer $q$ & 48 & 29 & 19 & 39.6 \\
\hline V21 & Luxer & 56 & 29 & 27 & 48.2 \\
\hline $\mathrm{V} 22$ & Luxer $\hat{\delta} \times$ Master B 오 & 55 & 29 & 26 & 47.2 \\
\hline V23 & Luxer $\hat{\delta} \times$ Lincoln 9 & 48 & 29 & 19 & 39.6 \\
\hline V24 & Luxer $\hat{\delta} \times$ Little Marvel $q$ & 47 & 29 & 18 & 38.3 \\
\hline V25 & Luxer $\hat{o} \times$ Sugarless 우 & 48 & 29 & 19 & 39.6 \\
\hline
\end{tabular}

Euclidian distance (Romesburg, 1990) was calculated and used for measuring the similarity between the parent varieties and their hybrids using the computer software program Community Analysis Package 4.0 (CAP) developed and produced by Seaby and Henderson (2007). The CAP software was also used for cluster analysis to measure the relationships between the varieties based on similarity estimates using the WARD tree building method. The cluster analysis was also performed using the NT-SYS-pc program version 2.2 (Rohlf, 2006) and two types of trees were constructed, one using the unweighted pair group method with arithmetic averages (UPGMA) proposed by Sokal and Michener (1958) and the other using Neighbor joining (NJ) method (Saitou and Nei, 1987).

Egypt. J. Bot., Vol. 55, No. 1 (2015) 


\section{Results}

The results showed varying degrees of variation in the examined morphological traits of the pea varieties and lines. In qualitative traits, high level of variation was observed in leaf area, degree of leaf dentation, leaf apex and tendril branching and low level of variation was observed for pod ends, pod color and texture, seed color and surface and color of seed helium. The results indicated that Var. Master B and Var. Luxer showed higher values for most of the growth traits and yield parameters in comparison with other parents (Lincoln, Little Marvel and Sugarless). The plants of Var. Sugarless, the only leafless variety that has more tendrils, showed the least measurements of vegetative traits and productivity parameters. The two hybrids of Var. Master B and Var. Luxer (V5 and V22) significantly surpassed the highest parental genotypes for days to flowering and fruiting and also productivity. The hybrids of Var. Little Marvel and Var. Sugarless (V14 \& V19) required longer time to flowering and fruiting than their parents. The hybrids of Var. Luxer and Var. Master B showed improved vegetative traits. On the other hand, hybrids of Var. Sugarless and Var. Master B were better than their parents in their yield parameters. Data on morphological variations are given in Hamouda (2012) and are available upon request.

The 19 SSR primer pairs amplified a total of 93 bands (alleles) in the 25 pea genotypes comprised of 63 polymorphic, 28 monomorphic and 2 unique bands. The number and types of bands and the percentage of polymorphism in each genotype as revealed by all primers are given in Table 2 . The number of total bands and polymorphic bands and the percentage of polymorphism in the five parent varieties were generally higher than their corresponding values in their hybrid lines. A maximum number of 72 bands was scored in Var. Master B and include 43 polymorphic bands including two unique bands scoring 59.97\% polymorphism. The other four varieties showed lower percentages of polymorphism; the two parents Lincoln and Little marvel have identical percentage of $51.6 \%$; the variety Sugarless has a percentage of $50.0 \%$. The hybrid lines Lincoln x Little Marvel, Lincoln x Sugarless and Little Marvel x Sugarless showed lower proportion of polymorphism $(34.1 \%, 35.6 \%$ and $36.9 \%$ respectively). On the other hand, the two hybrid lines (Luxer x Master B and Master B x Little Marvel) showed higher percentage of SSR polymorphism (47.2\% and 49. 1\%) compared to other hybrid lines. The other 17 hybrids have intermediate percentages of polymorphism ranging between $38.3 \%$ in the two hybrid lines Little Marvel $\mathrm{x}$ Luxer and Sugarless x Master B to 45.3\% in the hybrid line Master B x Lincoln.

Examples of the SSR fingerprinting profiles are illustrated in Fig. 1A-E. Two unique bands, both of them are recorded in Var. Master B by the two primers AA-473 and AD-141 (Fig. 1B and 1C) whereas primer AF-016458 showed no variation among the examined genotypes (Table 2 and Fig. 1D). In the profile of primer AA-473 (Fig. 1B), two alleles are common to all genotypes but one of them is missing from the profile of the two genotypes V14 \& V15; both are hybrids of the Var. Little Marvel with the two varieties Sugarless and Luxer. Some primers revealed loci and alleles that are characteristic for some genotypes; examples include primer A-6 (Fig. 1A) that produced one allele with a molecular size of 300 in the fingerprinting profile of the two genotypes V23 
and V 25 (two hybrids of Var. Luxer with Var. Lincoln and Var. Sugarless). However, the same primer produced an allele $(250 \mathrm{bp})$ in the genotypes V01, V03 and V05 (Var. Master B and two of its hybrids Var. Little Marvel and Var. Luxer) as well as the genotypes V10, V14, V15 and V20, which are all hybrid lines of the varieties Lincoln, Little Marvel, Sugarless and Luxer (Table 2).

Other prominent examples for characteristic SSR markers include the production of a $500 \mathrm{bp}$ allele by the primer AD-141 (Fig. 1C) in the genotypes of the five varieties (V01, V06, V11, V16 and V21) and the hybrid lines of Var. Master B and Var. Lincoln (V02). The same primer produced a $400 \mathrm{bp}$ allele in the fingerprinting of Var. Master B (V01) and five of its hybrid lines; two as a female parent with Var. Little Marvel and Var. Luxer (V03 \& V05), and three as male parents with Var. Lincoln, Var. Sugarless and Var. Luxer (V7, V17 \& V22). The primer B-16 (Fig. 1E) produced a $380 \mathrm{bp}$ allele that was characteristic for the four varieties Master B, Lincoln, Little Marvel and Luxer (V01, V06, V11, and V16). In the profile of this primer one allele was revealed in 23 genotypes but was absent in the profile of V20 and V25 (both are hybrid lines produced by the cross and reciprocal cross of the two varieties Sugarless and Luxer).
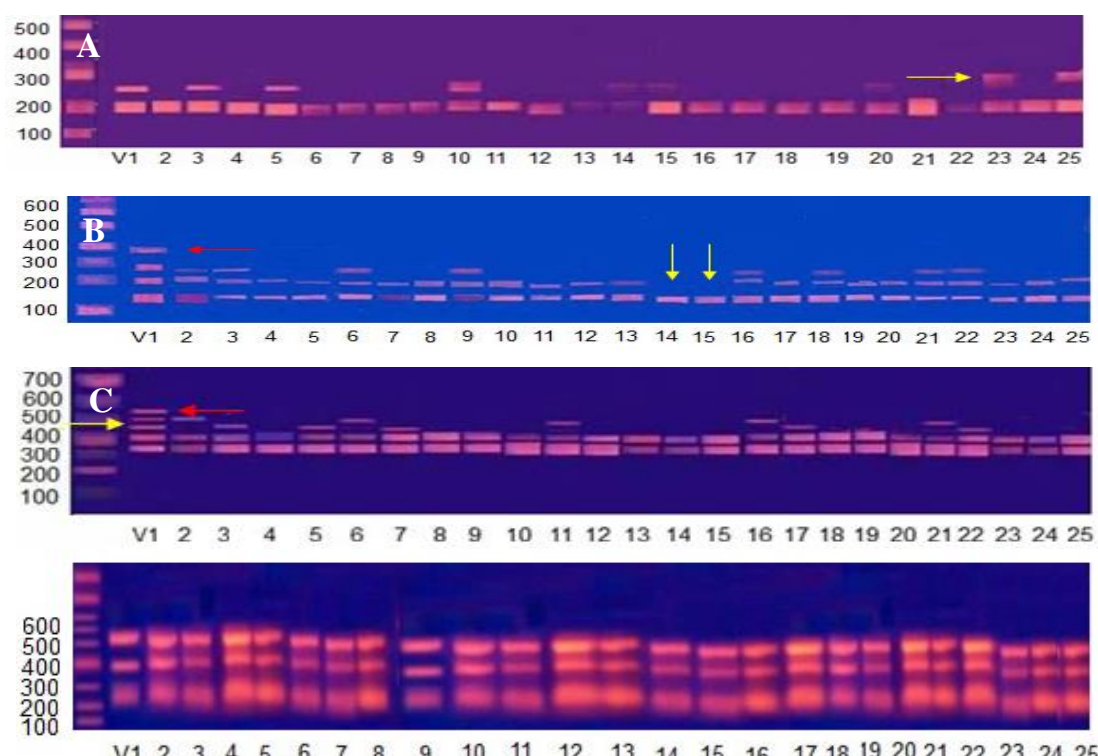

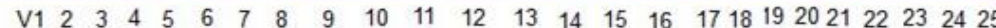

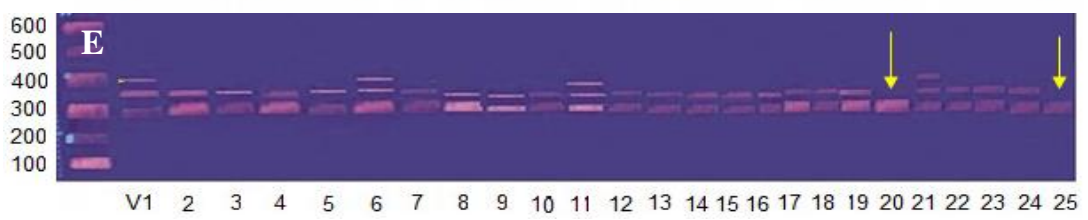

Fig. 1. Examples of the SSR profiles produced in the five varieties of pea and their hybrids by five of the primer pairs used in this study; $A=\operatorname{Pr}$. A-6, B = Pr. AA-473; C = Pr. AD-141; D = Pr. AF-016458 and E = Pr. B-16. Varieties and hybrids are numbered $V 1$ to 25 as in table 2 and primer sequences are given in Table 2. Yellow arrows illustrate polymorphic bands and red arrows indicate unique bands.

Egypt. J. Bot., Vol. 55, No. 1 (2015) 
Analysis of genetic diversity among the pea varieties and their hybrids based on morphological variation and SSR polymorphism produced UPGMA, NJ and CAP trees of similar topology. In all trees, a small group comprised of seven genotypes representing Var. Sugarless (V16) and most of its hybrids i.e. V19 (Sugarless x Little Marvel), V18 (Sugarless x Lincoln), V9 (Lincoln x Sugarless), V17 (Sugarless x Master B), V 20 (Sugarless x Luxer) and V25 (Luxer x Sugarless) were clearly separated from the other 18 genotypes. In a UPGMA tree constructed using the NT-SYS-pc (Fig. 2), the large group comprised of 18 genotypes is differentiated into four clusters; cluster 1 is comprised of Var. Little Marvel (V11) and three of its hybrid lines; V15 (Little Marvel x Luxer), V14 (Little Marvel x Sugarless) and V24 (Luxer x Little Marvel). Cluster 2 is comprised of four hybrids of varieties Little Marvel and Lincoln. Cluster 3 is comprised of these two varieties and two hybrid lines of Lincoln and Master B. Cluster 4 of group II is composed of six hybrid lines of the Var. Master B (Fig. 2).

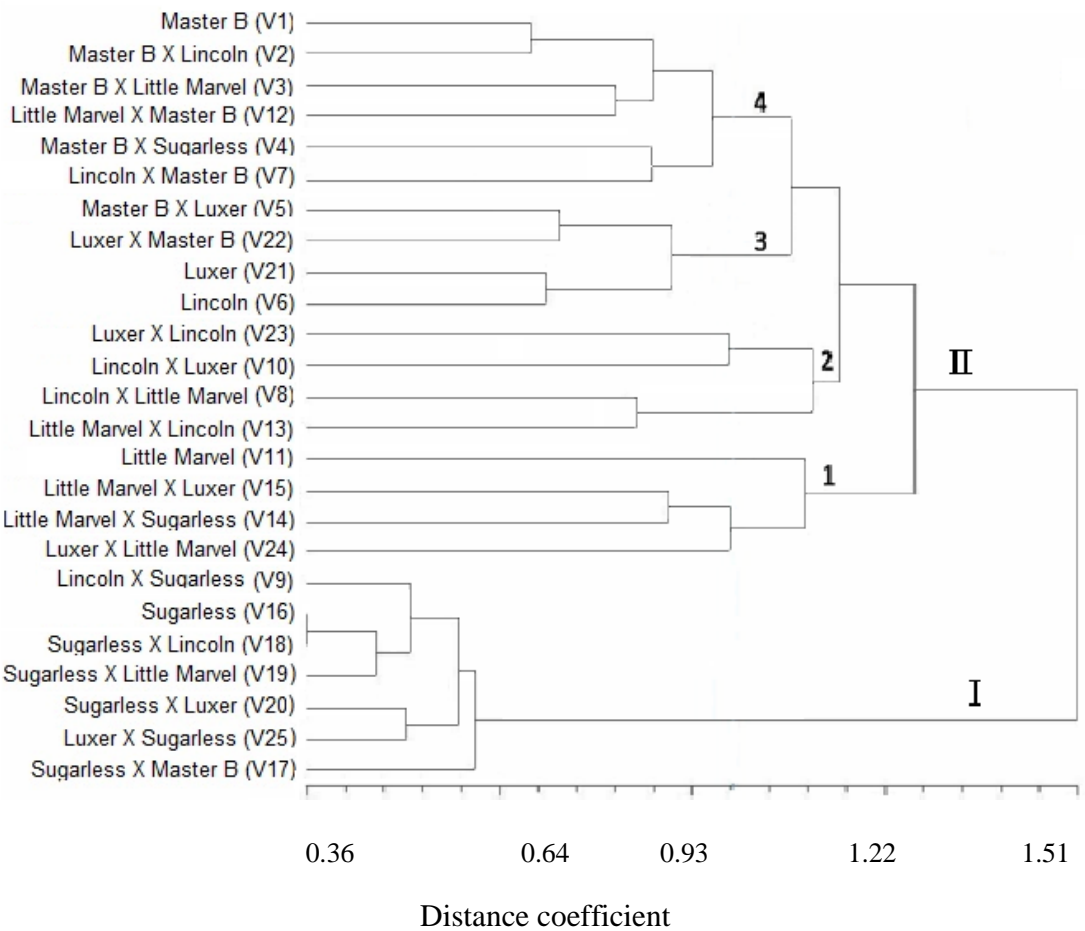

Fig. 2. UPGMA tree constructed using NT-SYS-pc illustrating the genetic distance among the five pea varieties and their hybrid lines based on variation in morphological traits. 
Genetic diversity among the examined genotypes, based on SSR fingerprinting as expressed by a WORD tree constructed by CAP software is illustrated in Fig. 3. The large group is comprised of two subgroups; one of nine genotypes comprising the Var. Little Marvel (V11) and its two hybrids; Little Marvel x Lincoln (V13) and Little Marvel x Sugarless (V14) in one cluster and Var. Lincoln (V06) and its hybrids Lincoln x Little Marvel (V08), Lincoln x Luxer (V10), Little Marvel x Luxer (V15) as well as Luxer x Lincoln (V23) and Luxer x Little Marvel (V24) as a second cluster. The second subgroups is composed of eight genotypes in two clusters; one comprising Var. Master B (01) and two of its hybrids with Var. Luxer (V05; V22) as well as Var. Luxer (V21). The other cluster is composed of five hybrids of Master B i.e. Master B x Lincoln (V02), Master B x Little Marvel (V03), Lincoln x Master B (V07), Master B x Sugarless (V04) and Little Marvel x Master B (V12). The genetic relationships based on the analysis of combined data of morphological variation and SSR polymorphism closely resembled the tree based on the analysis of SSR data.

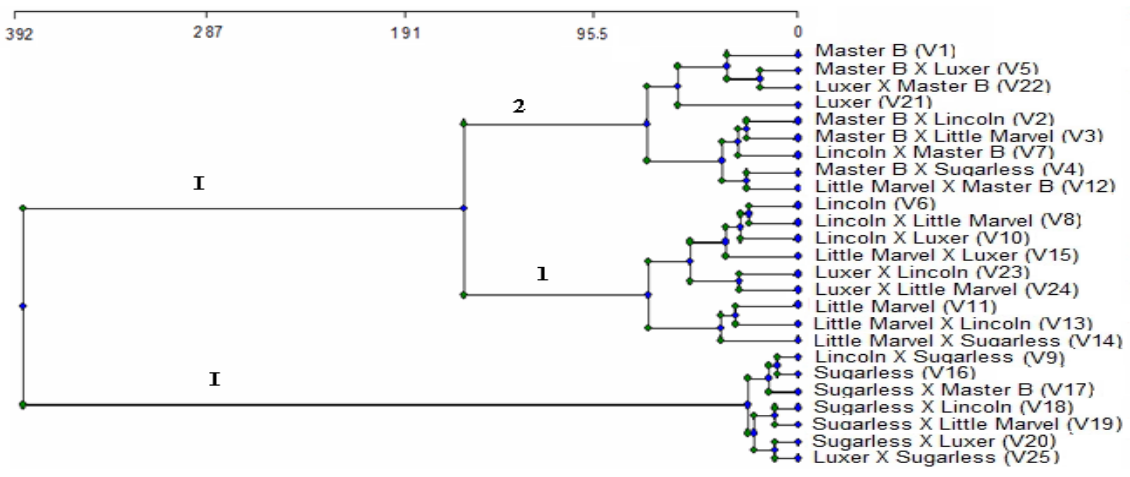

Fig. 3. WARD tree constructed using the CAP software illustrating the genetic distance among the five varieties of pea and their hybrid lines based on SSR polymorphism.

\section{Discussion}

Morphological traits are important for pea description and mostly influenced by consumer's preference and natural selection and are used for selection and confirmation of hybrid progeny (Ghafoor et al., 2005). The measurements of morphological traits clearly indicated that hybrids generally have higher values compared to their parents (Hamouda et al., 2012). This is congruent with the suggestion that hybridization breeding improves the productivity and yield as reported by Sarawat et al. (1994), and confirmed by Ceyhan et al. (2008) and Kosev et al. (2012). These observations are consistent with the reports by Ceyhan et al. (2008) and Kosev et al. (2012) who analyzed the inheritance of quantitative traits such as plant height, days to first pod, number of pods per

Egypt. J. Bot., Vol. 55, No. 1 (2015) 
plant, number of seeds per plant, seed weight per plant and number of fertile nodes per plant of parental components.

The low SSR polymorphism detected among the examined genotypes is consistent with the findings of a number of authors who reported that SSR markers are low but suitable for cultivars identification (Varshney et al. 2005; Loridon et al., 2005; Nasiri et al., 2009 and Sarıamis et al., 2010). Detailed description of SSR profiles and identification of alleles that are specific to certain genotypes indicate variation among the examined genotypes; details of SSR profile correlation with yield are available on request. These results agree with the findings of Sarkamış et al. (2010) who reported that the heterozygosity was lower than the expected heterozygosity in a germplasm collected from Turkey using morphological and SSR markers.

However, the levels of SSR polymorphism detected in the studied genotypes of peas are lower than the levels reported by Choudhury et al. (2006) on 24 of the most popular and widely adapted varieties who scored $74.8 \%$ polymorphism. Another major study that was done by Loridon et al. (2005) utilizing 309 SSR markers for the level of polymorphism in 110 varieties of pea in Canada, showed $73 \%$ of the markers were polymorphic. However, Tar'an et al. (2005) recorded $51 \%$ polymorphism using 65 varieties and 21 wild accessions of different pea subspecies. This percentage is similar to the level of polymorphism uncovered in the varieties of pea used in this study.

In the present investigation, the trees illustrating genetic diversity among the examined genotypes, based on morphological traits, as well as trees based on SSR markers are similar; each pea variety and its hybrids are often grouped together. In the meantime the complementation of the different marker types for estimating genetic similarity maximizes the benefits of the features of each type and in the types of polymorphism that they detect (Innan et al., 1997). The genetic diversity as outlined in the above three trees and other similar trees not presented here show significant correlation among molecular and morphological data that may due to the expression of genes to respective phenotype of morphology. In this respect, the results of this study are congruent with the results of Baranger et al. (2004) who reported significant correlation between molecular and morphological data. The significant correlations indicate that these independent sets of evidences likely reflect the same pattern of genetic diversity and validate the use of SSR fingerprinting for genetic diversity estimation and also for determining the relatedness of plant genotypes.

In conclusion, our results confirm that SSR markers can successfully differentiate between parent and hybrid genotypes of pea and provide valuable markers for breeding new lines of this important legume crop. This is congruent with the view that SSR markers reveal a large number of polymorphic loci with an excellent coverage of an entire genome and allow scoring of polymorphism at any developmental stage (Sarıkamış, et al., 2010; Marie and Esther, 2010). These results further indicate that combinations of morphological and molecular 
markers are valid sources of information for the estimation of genetic diversity in pea (Tihomir et al., 2009). The reported SSR markers in the examined pea varieties and their hybrids are valuable markers for further selection of some of the new hybrids as new varieties of pea.

\section{References}

Ana Paula, R., Josefina, H., Maria, H., Marta, S. and Antonio, M. (2008) Sources of variation for sustainable field pea breeding. Euphytica, 166: 95-107.

Baranger, A., Aubert, G., Arnau, G., Laine', A.L. Deniot, G., Potier, J., Weinachter, C., Lejeune-He'naut, I., Lallem, J. and Burstin, J. (2004) Genetic diversity within Pisum sativum using protein and PCR-based markers. Theor. Appl. Genet, 108: 13091321.

Bliss, F.A., (2007) Education and preparation of plant breeders for careers in global crop improvement. Crop. Sci., 47: 250-261.

Burstin J., Deniot, G., Potier, J., Weinachter, C., Aubert, G. and Baranger, A. (2001) Microsatellite polymorphism in Pisum sativum. Plant. Bree.,120: 311-317.

Ceyhan E., Ali, A. M.and Serdar, K. (2008) Line X tester analysis in pea (Pisum sativum L.): Identification of superior parents for seed yield and its components. Afr. J. Biotech, 7: 2810-2817.

Choudhury P., Tanveer, H. and Dixit, G.P. (2006) Identification and detection of genetic relatedness among important varieties of pea (Pisum sativum L.), grown in India. Genetica, 130: 183-191.

Cieslarová J., Hýbl, M., Griga, M. and P. Smýkal, (2012) Molecular analysis of temporal genetic structuring in pea (Pisum sativum L.) ccultivars bred in the Czech Republic and in the Former Czechoslovakia since the mid. $20^{\text {th }}$ century. Czech. J. Genet. Plant. Breed., 48: 61-73.

Ellis T. H. N. (2011) Pisum. In: "Wild Crop Relatives: Genomic and Breeding Resources" (Legume Crops and Forages) Kole C. (Ed.). Springer Verlag, BerlinHeidelberg, pp. 237-248.

Gatti, I., Espósito, M., Almirón, P., Cravero, V. and Cointry, E. (2011) Diversity of pea (Pisum sativum) accessions based on morphological data for sustainable field pea breeding in Argentina. Genet. Mol. Res., 31: 3403-10.

Ghafoor, A., Ahmad, Z. and Anwar, R. (2005) Genetic diversity in Pisum sativum and a strategy for indigenous biodiversity conservation. Pak. J. Bot., 37: 71-77.

Gong Y.M., Xu, S.C., Mao, W.H., Hu, Q.Z., Zhang, G.W., Ding, J. and Li, Y.D. (2010) Developing new SSR markers from ESTs of pea (Pisum sativum L.). J. Zhejiang Univ., Sci., B 11: 702-707.

Hamouda, M.M., (2012) Genetic variation of commercial varieties and hybrids of pea (Pisum sativum L.). Ph D thesis, Tanta University, Egypt.

Egypt. J. Bot., Vol. 55, No. 1 (2015) 
Heath, M.C. and Hebblethwaite, P.D. (1985) Agronomic problems associated with the pea crop. In: "The Pea Crop", P.D., Hebblethwaite. M.C. Heath, and T.C.K. Dawkins (Eds.). Butterworths, London, pp. 19-26.

Innan, I., Terauchi, R. and Miyashita, N.T. (1997) Microsatellite polymorphism in natural populations of the wild plant Arabidopsis thaliana. Genetics, 146: 1441-1452.

Knight, J. (2003) Crop improvement: A dying breed. Nature, 421: 568-570.

Kosev, V., Pachev', S. and Angelova (2012) Inheritance of quantitative traits in crosses between two Pisum sativum subspecies with particular reference to three breeding value. Russ. Acad. Sci., 48(1): 50-55.

Loridon, K., McPhee, K., Morin, J., Dubreuil, P., Pilet-Nayel, M.L., Aubert, G., Rameau, C., Baranger, A., Coyne, C., Lejeune-He`naut, I. and Burstin, J. (2005) Microsatellite marker polymorphism and mapping in pea (Pisum sativum L.). Theor. App. Genet., 111: 1022-1031.

Marie, J. C., and Esther, W. (2010) Evaluation of simple sequence repeat (SSR) markers for identification of peas varieties registered in Canada. Theor. Appl. Genet., 111: $1022-1031$

Nasiri, I. J., Haghnazari, A. and Saba, J. (2009) Genetic diversity among varieties and wild species accessions of pea (Pisum sativum L.) based on SSR markers. Afr. J. Biotechnol., 8: 3405-3417.

Nisar. M., A. Ghafoor, and Khan, M. R. (2011) Phenotypic variation in the agronomic and morphological traits of Pisum sativum L. germplasm obtained from different parts of the world. Genetica, 47: 25-31.

Rohlf, F. (2006) NTSYS-pc: Numerical Taxonomy System (Ver. 2.2). Exeter Publishing, Ltd., Setauket.

Romesburg, H.C. (1990) "Cluster Analysis for Researchers". Robert E. Krieger Pub. Co. Florida, USA.

Roy, F., Boye, J.I. and Simpson, B. K. (2010) Bioactive proteins and peptides in pulse crops: Pea, chickpea and lentil. Food Res. Int., 43: 432-442.

Saeed, M., Sartaj, B. Muhammad, A. and Ghafoor, A. (2009) Genetic diversity for determining yield potential and selection criteria in Pisum sativum genetic. Pak. J. Bot., 41: 2987-2993.

Saitou, N. and Nei, M. (1987) The neighbor-joining method: A new method for reconstructing phylogenetic trees. Mol. Biol. Evo.l, 4: 406-425.

Samec, P., Posvec, Z., Stejskal, J., Nasinec, V. and Griga, M. (1998) Cultivar identification and relationships in Pisum sativum L. based on RAPD and isozymes. Plant Biol., 41: 39-48.

Santalla, M., Amurrio, J.M., and De Ron, A.M. (2001) Food and feed potential breeding of green, dry and vegetable pea germplasm. Can. J. Plant Sci., 81: 601-610.

Egypt. J. Bot., Vol. 55, No. 1 (2015) 
Sarawat, P., Stoddard, F.L., Marshall, D.R. and Ali, A. (1994) Heterosis for yield and related characters in pea. Euphytica, 80: 39-48.

Sarıkamış, G., Yanmaz, R., Ermiş, S., Bakır, M. and Yükse, Y. (2010) Genetic characterization of pea (Pisum sativum) germplasm from Turkey using morphological and SSR markers. Genet. Mol. Res., 9: 591-600.

Seaby, R. and Henderson, P. (2007) Community Analysis Package 4.0. Searching for structure in community data. Lymington, UK.

Simioniuc, D., Uptmoor, R, Friedt, W. and Ordon, F. (2002) Genetic diversity and relationships among pea cultivars revealed by RAPDs and AFLPs. Plant Breed., 121: 429-435.

Smýkal, P., Aubert, G., Burstin, J., Clarice, J., Noel, T.H., Andrew, J., Ford, R., Hýbl, M., Macas, J., Neumann, P., McPhee, K., Robert, R., Diego, R., Jim, W. and Tom, D. W. (2012) Pea (Pisum sativum L.) in the genomic Era. Agronomy, 2: 74-115.

Smýkal, P., J. Horacek, R. Dostalova, and M. Hýbl, 2008. Variety discrimination in pea (Pisum sativum L.) by molecular, biochemical and morphological markers. Theor. Appl. Genet., 49: 155-166.

Sokal, R., and Michener, M. (1958) A statistical method for evaluating systematic relationships. Univ. Kansas Sci. Bull., 38: 1409-1438.

Tar'an, B., Zhang, C., Warkentin, T., Tullu, A. and Vandenberg, A. (2005) Genetic diversity among varieties and wild species accessions of pea (Pisum sativum L.) based on molecular markers, morphological and physiological characters. Genome, 48: 257-272.

Tihomir, C., Marijana, T., Svetislav, P., Snjezana, B., Sonja, G. and Vinko, K. (2009) Genetic diversity of pea (Pisum sativum L.) genotypes assessed by pedigree, morphological and molecular data. J. Food Agric. Environ., 7: 343-348.

Varshney, R.K., Graner, A. and Sorrells, M.E. (2005) Genic microsatellite markers: Their characteristics, development and application to plant breeding and genetics. Trends Biol., 23: 48-55.

Zhuang X., McPhee, K.E., Coram, T.E., Peever, T.L. and Chilvers, M.I. (2013) Development and characterization of 37 novel EST-SSR markers in Pisum sativum (Fabaceae). Applications in Plant Sciences 1(1): Doi: http://dx.doi. Org / 10.3732/apps. 1200249 .

Zong, X.X., Guan, J.P., Wang, S.M. and Liu, Q.C. (2008) Genetic diversity among Chinese Pea (Pisum sativum L.) landraces as revealed by SSR markers. Acta Agron. Sinica, 34: 1330-1338. 


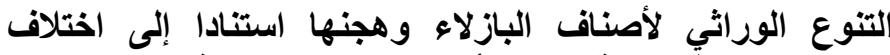

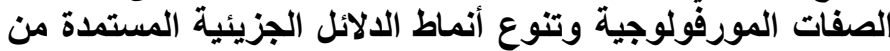 التتابعات القصيرة المتكررة}

$$
\begin{aligned}
& \text { عبدالفتاح بدر' وحنان إبراهيم سيد أحمد` ومروة محمود حمودة` وسلوى فهمى }
\end{aligned}
$$

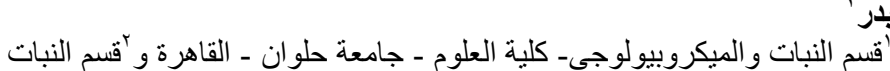

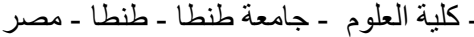

أجريت هذه الدراسة من أجل تقييم التنوع الور اثى بين خمسة أصناف من الباز لاء

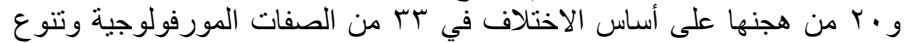

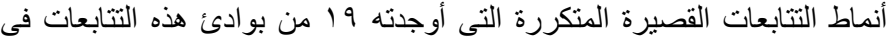

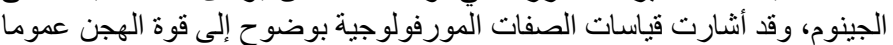

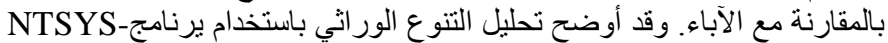

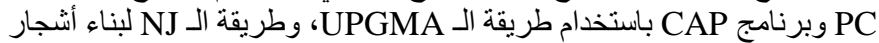

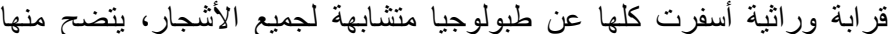

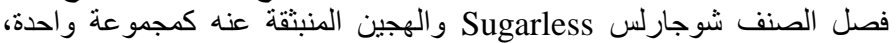

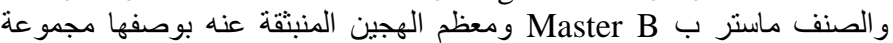

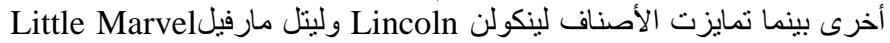

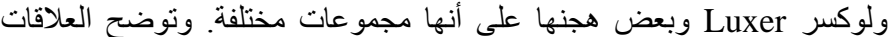

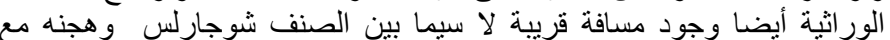

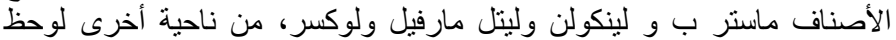

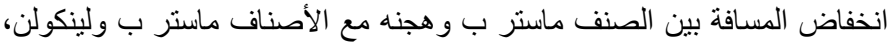

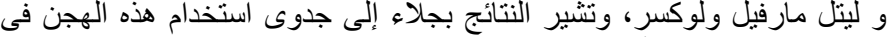
توجيه استتباط وتربية أصناف تجارية من الباز لاء. 